\title{
Current food chain information provides insufficient information for modern meat inspection of pigs
}

\section{Felin, Elina}

2016-05-01

Felin , E, Jukola , E , Raulo , S , Heinonen , J \& Fredriksson-Ahomaa , M 2016 , ' Current food chain information provides insufficient information for modern meat inspection of pigs ' , Preventive Veterinary Medicine , vol. 127 , pp. 113-120 . https://doi.org/10.1016/j.prevetmed.2016.03.007

http://hdl.handle.net/10138/223953

https://doi.org/10.1016/j.prevetmed.2016.03.007

cc_by_nc_nd

acceptedVersion

Downloaded from Helda, University of Helsinki institutional repository.

This is an electronic reprint of the original article.

This reprint may differ from the original in pagination and typographic detail.

Please cite the original version. 
1 Current food chain information provides insufficient information for modern meat

2

3 Felin Elina ${ }^{1}$, Jukola Elias ${ }^{2}$, Raulo Saara $^{3}$, Heinonen Jaakko ${ }^{4}$ and Fredriksson-Ahomaa Maria ${ }^{1}$ 4

$5{ }^{1}$ Department of Food Hygiene and Environmental Health, Faculty of Veterinary Medicine,

6 University of Helsinki, P.O Box 66, 00014 University of Helsinki, Finland;

7 elina.felin@helsinki.fi, maria.fredriksson-ahomaa@helsinki.fi

$8 \quad{ }^{2}$ HKScan Oyj, P.O Box 49, 01511 Vantaa, Finland; elias.jukola@hkscan.com

$9 \quad{ }^{3}$ Finnish Food Safety Authority, Zoonosis Centre, Mustialankatu 3, 00790 Helsinki, Finland;

10 saara.raulo@evira.fi

$11 \quad{ }^{4}$ Joensuu, Finland; jaakko.heinonen@1uke.fi

12 *Author for correspondence. Tel: +358-50-4110216; E-mail: elina.felin@helsinki.fi. 
ABSTRACT

27 Meat inspection now incorporates a more risk-based approach for protecting human health against meat-borne biological hazards. Official post-mortem meat inspection of pigs has shifted to visual meat inspection. The official veterinarian decides on additional post-mortem inspection procedures, such as incisions and palpations. The decision is based on declarations in the food chain information (FCI), ante-mortem inspection and post-mortem inspection. However, a smooth slaughter and inspection process is essential. Therefore, one should be able to assess prior to slaughter which pigs are suitable for visual meat inspection only, and which need more profound inspection procedures. This study evaluates the usability of the FCI provided by pig producers and considered the possibility for risk ranking of incoming slaughter batches according to the previous meat inspection data and the current FCI. Eightyfive slaughter batches comprising 8954 fattening pigs were randomly selected at a slaughterhouse that receives animals from across Finland. The mortality rate, the FCI and the meat inspection results for each batch were obtained. The current FCI alone provided insufficient and inaccurate information for risk ranking purposes for meat inspection. The partial condemnation rate for a batch was best predicted by the partial condemnation rate calculated for all the pigs sent for slaughter from the same holding in the previous year $(\mathrm{p}<0.001)$ and by prior information on cough declared in the current FCI $(\mathrm{p}=0.02)$ statement. Training and information to producers are needed to make the FCI reporting procedures more accurate. Historical meat inspection data on pigs slaughtered from the same holdings and well-chosen symptoms/signs for reporting, should be included in the FCI to facilitate the allocation of pigs for visual inspection. The introduced simple scoring system can be easily used for additional information for directing batches to appropriate meat inspection 
surveillance should be done and the information obtained from analyses should be used as part of the FCI.

Keywords: food chain information; meat inspection; pig; food safety; sensitivity; specificity

and animal health issues, meat is to be declared unfit for human consumption also if it indicates patho-physiological changes, anomalies in consistency or organoleptic anomalies (European Parliament and Council, 2004). If the change is local, partial condemnation is done and the abnormal tissue is removed by incision.

Meat inspection has been developed to incorporate a more risk-assessment based approach for protecting human health against meat-borne biological hazards. In regards to the most relevant pork-borne biological hazards of pig meat (Salmonella spp., Yersinia enterocolitica, Trichinella spp. and Toxoplasma gondii), only Trichinella spp. are detectable within the current post-mortem inspection (EFSA, 2011). A comprehensive pork carcass safety assurance system from 'farm to fork' is needed to ensure the effective control of meat-borne public health hazards, with the primary production stage playing an essential role in managing these risks (EFSA, 2011).

2 Moreover, the official post-mortem meat inspection of pigs shifted to visual meat inspection 3 in EU (European Commission, 2014) in 2014. Techniques such as routine palpations and 4 incisions are omitted from inspection procedures. This is because the risk of microbial cross- 
contamination is higher than the risk associated with any potential reduction in detection of conditions by not using these techniques. Current regulations allow the official veterinarian (OV) to decide on any additional post-mortem inspection procedures such as incisions and palpations. The decision can be based on one or any combination of the food chain information (FCI), ante-mortem inspection (including verification of animal welfare), postmortem inspection or any other data regarding the animal that might in the OV`s opinion indicate a possible risk to public health, animal health or animal welfare. Visual meat inspection is aimed to detect any observable abnormalities in carcasses. Palpation and incision procedures are carried out to fully inspect abnormal carcasses and offal to achieve a preliminary diagnosis and to decide on condemnations or if laboratory analysis are needed. The main deficiency, in these techniques, is that only conditions associated with gross lesions are detected while the most important pork-borne public health hazards are neglected (EFSA, 2011).

Slaughter batches of pigs with high frequency of lesions are not suitable for visual meat inspection. One should be able to identify which batches of slaughter pigs are suitable for visual meat inspection only, and which need more profound inspection procedures to ensure a more efficient slaughter and meat inspection process. To optimize procedures, meat inspectors should be able to focus on the examination of carcasses in which adverse conditions are suspected. Batches of pigs with high frequency of lesions should be slaughtered separately as they need a slower line speed and adequate human resources at trimming line. However, when based on ante-mortem inspection, such measures are often too late considering the practical arrangements at the slaughterhouse. On the day of slaughter it is possible, but laborious and impractical to change the slaughter order. In practice, the slaughter 
batches of pigs with high frequency of lesions should be recognized beforehand upon reliable and comprehensive FCI reporting.

EU-Regulation (EC) No. 853/2004 stipulates that adequate FCI must be presented to the slaughterhouse operator and to the OV no less than 24 hours before the arrival of the animals at the slaughterhouse. In Finland, all the largest slaughterhouses use a uniform FCI-form, which is used by the pig producers to make the declarations, which include the following:

1) any relevant health status data regarding the holding or the animals in question (for example salmonellosis, trichinellosis, erysipelas, anthrax etc.),

2) any restrictions on the holding imposed by the authorities,

3) any drug residues or unauthorized substances detected in animals or at the holding during the last year,

4) any pigs in the slaughter batch that have been treated with veterinary medicinal products that have a withdrawal period within the three months prior to slaughter,

5) certain symptoms and signs detected in the slaughter batch (in detail in Table 1),

6) anything else relevant considering slaughter,

7) contact information of the veterinary practitioner for the holding.

In Finland, the FCI forms are usually sent to the slaughterhouses electronically, and they do not routinely include any ante- and post-mortem inspection data on previous batches of animals that had originated from the same holding. Typically the slaughterhouses keep such historical information in their own records, available to the OV (personal communication, Elias Jukola). Farmers have access to the meat inspection data concerning their farm via Sikava (Stakeholders health and welfare register for pig herds in Finland, www.sikava.fi). 
124 The aims of this study were to assess the usability of the FCI provided by the pig holdings

125 that sent the animals for slaughter and to evaluate the possibility of risk ranking of incoming

126 slaughter batches according to the previous meat inspection data and the current FCI

127 statements. As the risk of condemnation is mostly related to animal health and meat quality

128 issues, serological testing were also included to emphasize the most relevant pork-borne

129 public health hazards. The associations between the current and the historical meat inspection

130 results, the FCI and the results from serological tests of slaughter batches of finishing pigs,

131 were analyzed.

\section{MATERIALS AND METHODS}

\section{$134 \quad 2.1$ Data}

135 Eighty five slaughter batches of fattening pigs comprising 8954 animals were randomly selected at a slaughterhouse that receives animals from across Finland during the November 2012 to February 2013 period. Approximately 30\% of the finishing pigs in Finland are slaughtered in this slaughterhouse. The slaughter batch sizes ranged from 20 to 271 pigs (a median of 87 pigs / batch). The mortality rate for each slaughter batch during last three

140 months of finishing was provided by Sikava (Stakeholders health and welfare register for pig 141 herds in Finland). The FCI, provided by the respective pig producers, and the meat inspection 142 results were provided by the slaughterhouse. The holding of the pigs was traced by their slap 143 marks. A total of 80 pig-production holdings were identified, that in all produce over $10 \%$ of

144 the fattening pigs slaughtered annually in Finland. The meat inspection data that was used for 145 the analyses concerned the slaughter batches that were sent from the same holdings during the 146 previous year and covered more than 280000 pigs. (Approximately 2100000 fattening pigs 147 are slaughtered annually in Finland (http://statdb.luke.fi/PXWeb/pxweb/en/LUKE/ ).) 
149 The meat inspection results collected from the slaughterhouse generally correspond well with

150 the national meat inspection statistics for the same year (Table 1, C). The only variation was 151 observed for pleuritis rates as they were high in this particular slaughterhouse due to even the

152 smallest lesions being reported, though those might not lead to condemnations.

154 For the purpose of this study, meat juice samples were collected from all the selected 85 155 slaughter batches (3-10 samples/batch). The meat juice was screened for antibodies for 156 Salmonella spp., pathogenic Yersinia spp., Trichinella spp. and Toxoplasma gondii by using 157 the appropriate commercial enzyme linked immunosorbent assay (ELISA) kits. A batch was 158 considered positive when antibodies were detected in one or more of the samples. The 159 serological analyses are described in detail in another publication by the authors (Felin et al., 160 2015). Table 1 describes in detail the data collected on the selected slaughter batches.

\section{TABLE 1 Data collected on randomly selected 85 slaughter batches of finishing pigs}

164 None of the holdings declared salmonellosis, trichinellosis or any restrictions imposed by the 165 authorities, and erysipelas was notified by only three holdings (Table 1) therefore this 166 information was excluded from the analysis. The declaration on the occurrence of constant coughing during the three months prior to slaughter was coded for statistical analysis as the following: not declared $=0$, a bit $=1$, a lot $=2$. None of the holdings declared a lot of constant 169 coughing.

\section{Statistical analysis and assumptions}

171 Associations between the variables derived from the collected data were analyzed using

172 Pearson correlation coefficients (r). Differences between mean values of groups were tested 173 using independent sample t-tests. The values of the t-tests were transformed using the arcus 
174 sine of the square root transformation to achieve homogeneous variances and approximately

175 normal distributions. P-values $<0.05$ were considered to indicate statistical significance.

176 Linear regression analysis with different stepwise selection algorithms of previous meat

177 inspection reports and of current FCI that may indicate high condemnation rates in

178 forthcoming slaughter batches were used to reveal predictive factors. As batches with high

179 frequency of lesions need more profound inspection procedures, the partial condemnation rate

180 was assumed to be the best indicator in our study to reveal retrospectively, whether or not a

181 slaughter batch could have been suitable for visual meat inspection. The response variables in

182 the regression analyses were the partial condemnation rate, the organ condemnation rate and

183 the sum of the partial and total condemnation rate. Responses were transformed by using the

184 arcus sine of the square root transformation. The residuals had approximately a normal

185 distribution and homogenous variance due to this transformation. Regression models were

186 also estimated for untransformed responses using the regressors found in the stepwise

187 procedures. Analyses were computed using the analytical software package SPSS® Statistics

188 Version 22 (IBM Corp., New York, USA). The results from the scoring system and current

189 meat inspection were classified into a two-by-two contingency table. Sensitivity, specificity

190 and accuracy were calculated as corresponding descriptive test parameters.

\section{RESULTS}

\subsection{Associations between FCI regarding the batch, mortality during fattening and meat} inspection results

195 Slaughter batches were divided into two groups according to the FCI reports: a group of 196 batches with nothing to declare in FCI $(n=22)$ and a group of batches with something to

197 declare $(n=63)$. Slaughter batches with "nothing to declare" in the FCI had statistically higher 198 condemnation rates of livers than the batches with something to declare $(16.0 \%$ and $6.6 \%$, 
$\mathrm{p}<0.01)$. The organ condemnation rate was also higher for the batches with nothing to declare,

200 but this difference was not statistically significant $(2.9 \%$ and $1.1 \%, \mathrm{p}=0.13)$.

201

202 Constant coughing was declared in only four batches during the three months prior to 203 slaughter (Table 1, B), which lowers the generality of the results. These four batches had 204 higher mean arthritis prevalences $(6.4 \%$ and $1.5 \%, \mathrm{p}<0.01)$, partial $(8.8 \%$ and $4.8 \%, \mathrm{p}=0.05)$ 205 and total $(0.8 \%$ and $0.2 \%, \mathrm{p}=0.07)$ condemnation rates than the other batches. The difference 206 between the partial and the total condemnation rate was not statistically significant. In 207 contrast, pneumonia and pleuritis rates observed at meat inspection were not prominent for 208 batches for which coughing was declared in the FCI.

210 Batches with a FCI declaration on pigs medicated within last three months prior to slaughter 211 had lower mean condemnation rates for livers $(6.3 \%$ and $12.2 \%, \mathrm{p}<0.01)$.

Those batches with declarations on lameness had statistically significantly higher mean 214 prevalences of pleuritis $(45.3 \%$ and $33.1 \%, \mathrm{p}=0.04)$ at meat inspection. No other statistically 215 significant differences were found.

217 The FCI declaration rates, i.e. the percentages of pigs in the batch declared to have a 218 symptom/sign for one of the following: hernias, abscesses/lumps, and lameness correlated 219 with higher pleuritis rates at meat inspection $(\mathrm{r}=0.24,0.26,0.31$ and $\mathrm{p}=0.03, \mathrm{p}=0.02, \mathrm{p}<0.01$ 220 respectively). The FCI declaration rate for bitten tails correlates with higher pneumonia rates $221(\mathrm{r}=0.25, \mathrm{p}=0.02)$ at meat inspection. The FCI declaration rate for lameness correlates with more observations on bitten tails $(r=0.26, p=0.02)$ at meat inspection. The two last mentioned 223 results were based on data regarding only a single batch for each result i.e. two separate 
batches. One batch with $29 \%$ pneumonia found at meat inspection and another batch with $7 \%$

225 of lameness declared in FCI. When these batches were discarded from the analysis, no correlations were found.

The percentage of bitten tails declared in the FCIs correlated with the observations on bitten tails at meat inspection, but this correlation was not statistically significant $(r=0.20, p=0.06$, Figure 1). However, when the zero-values are discarded, the correlation is clear $(\mathrm{r}=0.56$, $231 \mathrm{p}<0.01)$ (Figure 1).

\section{FIGURE 1 The correlation between the food chain information and meat inspection}

\section{4 reports on bitten tails of finishing pigs from 85 slaughter batches}

There were no statistically significant correlations between the rate for batch mortality during was found between batch mortality rate and pneumonia rate detected at meat inspection $(\mathrm{r}=0.19, \mathrm{p}=0.09)$. On the other hand, the correlation was statistically significant when only

240 those batches with pneumonia detected at meat inspection were analyzed $(r=0.26, p=0.04)$.

242 There were clear positive correlations $(\mathrm{r}=0.49-0.71, \mathrm{p}<0.001)$ between FCI declaration rates 243 for hernias, abscesses/lumps, abnormalities in gait and bitten tails.

245 Associations between the prior information for a particular batch that declared something in 246 the FCI and meat inspection results of the same batch were analyzed $(n=63)$. This was done 247 because it was suspected that some of the FCIs with "nothing to declare" were not reliable. 248 No new associations were found. 
250 The prior information on the batches declared in the FCI were analyzed by one declaration 251 category at a time, including only those batches with positive declarations (Table 1, B). A 252 positive correlation was found between the declared percentage of pigs with hernias and the 253 total condemnation rate $(r=0.38, p=0.04)$. Again, the result was determined by one batch with 254 high total condemnation rate of $2.8 \%$. When that batch was excluded from the analysis, no 255 correlation $(\mathrm{r}=0.01, \mathrm{p}=0.92)$ was found. No other new associations were found by this 256 analysis.

\subsection{Associations between meat inspection results of current and previous batches from} the same holding

Several statistically significant $(\mathrm{p}<0.05)$ correlations between the meat inspection results of all pigs sent for slaughter the previous year and the meat inspection findings from the currently slaughtered batch were found at the holding level (Table 2). No correlations were found for total condemnation, pneumonia and arthritis.

TABLE 2 Statistically significant correlations $(p<0.05)$ between meat inspection results for the currently slaughtered batch $(n=85)$ and between meat inspection results for pigs sent from the same holding for slaughter the previous year

\subsection{Correlations between serology and meat inspection results}

270 There were no statistically significant correlations found between any of the tested 271 seroprevalences and current meat inspection findings at the slaughter batch level. A negative 272 correlation was found between the seroprevalence within a batch of a pathogenic Yersinia 273 spp. and the number of pigs in that batch $(r=-0.33, p<0.01)$. A positive correlation was found 
274 between the current seroprevalence of Salmonella and the prevalence of pneumonia $(\mathrm{r}=0.28$, $275 \mathrm{p}<0.01)$ and also pleuritis $(\mathrm{r}=0.24, \mathrm{p}=0.02)$ in the previous year findings of the meat 276 inspection.

\subsection{Linear regression predicting the meat inspection results}

279 Several variables for condemnation (partial condemnation rate, organ condemnation rate and 280 the sum of the partial and total condemnation rate) derived from the meat inspection data were analyzed to determine the most suitable predictors to ascertain whether the current batch would have been suitable for visual meat inspection. Total condemnations in the current batches were so rare that it was not considered relevant as a factor.

Figure 2 The partial condemnation rates of 85 slaughter batches of finishing pigs and the batches from the same holding during the previous year

While analyzing the predictors for the current partial condemnation rate, an extreme value

(Figure 2, previous year's partial condemnation rate 24\%) for one of the batches was discarded from the analyzed data since it would have resulted in illogical models. All the variables of previous meat inspection reports and the information on the batch declared in the FCI, were tested as the explanatory variables. The two exceptions to this were the previous year's organ condemnation rate and previous year's rate of bitten tails, both of which had 54

294 missing values.

The partial condemnation rate of the previous year was revealed as the most important variable for predicting whether or not the current batch would have been suitable for visual 298 meat inspection. The regression analyses revealed the best predictors for the partial 
condemnation rate of the batch were the partial condemnation rate of the previous year $300(\mathrm{p}<0.001)$ and the declared cough in the current FCI $(\mathrm{p}=0.02)$. Total condemnations were so 301 rare, that the predictors were also the same for the sum of the total and partial condemnation 302 rate. When the untransformed partial condemnation rate was predicted by the two best 303 predictors, the adjusted $\mathrm{R}^{2}$ was 0.31 , the regression coefficient of the partial condemnation 304 rate of the last year was 0.93 and the coefficient of the declared cough in the FCI was 4.5.

305 This means that for every additional percent in partial condemnation rate of the last year the 306 partial condemnation rate of the current batch increased by an average of 0.93 percent units 307 and that the predicted partial condemnation rate increased by 4.5 percent units if coughing 308 was reported in the slaughter batch.

310 The best predictor for the organ condemnation rate of the current batch was the organ 311 condemnation rate of the previous year $(n=31, p=0.03)$. When the untransformed organ 312 condemnation rate was predicted by the best predictor, the adjusted $\mathrm{R}^{2}$ was 0.15 , regression 313 coefficient of the organ condemnation rate of the last year was 0.19 .

\section{$315 \quad 3.5$ Scoring}

316 Two threshold limits were set to delineate categories, namely: "suitable for visual meat 317 inspection" and to "need additional inspection procedures", which was to ease decision318 making for the allocation of the slaughter batches in advance. The statistically significant 319 factors were the previous year's partial condemnation rate $(\%)$ and the FCI regarding the 320 current slaughter batch declaring on occurrence of constant coughing during the three months 321 prior to slaughter. Threshold limits for scoring was calculated by using the 10- and 90 -deciles 322 from the previous year's condemnation rates: 0 points for below the 10-decile, 1 point for 10- 
to 90 -decile, and 2 points above the 90-decile. The declaration for a constant cough added

324 another two points.

TABLE 3 Scoring of 85 batches of slaughter pigs according to food chain information

Note that, only for four batches were declared to have had constant coughing within the three months prior to slaughter (Table 1, B), which compromises the results. There was a significant positive correlation $(\mathrm{r}=0.32, \mathrm{p}<0.01)$ between declarations on constant coughing and current partial condemnation rates even when only the batches with last year's partial condemnation rate $\leq 8 \%(\mathrm{n}=76)$ were considered.

Eight batches (Table 3) were given a score of zero points, which indicated that they would have been suitable for visual meat inspection. Analysis of the meat inspection reports for these batches show that they were actually suitable for visual meat inspection (partial condemnation rate $1.4-3.8 \%$, organ condemnation rate $0.0-3.5 \%$.

A total of 64 batches (Table 3) were scored with one point. An analysis of the meat inspection 341 reports of these batches show that the majority of these batches were suitable for visual meat 342 inspection. However, five of the batches could not be regarded as only suitable for visual 343 meat inspection because of a high rate of partial condemnations (9-13\%), and these could not 344 have been detected beforehand with the suggested scoring system. The FCI on these five 345 batches revealed that in only two the pigs had been treated with veterinary medicinal products 346 within the three months prior to slaughter, and their historical meat inspection data and 347 mortality rates during fattening did not markedly differ from the mean. The result indicates 
348 that the available prior information was insufficient to discriminate all the relevant batches

349 beforehand.

351 Thirteen batches (Table 3) were considered to qualify for additional inspection procedures as 352 they had scores of two points or more (9 batches with last year's partial condemnation rate 353 over $8 \%$ and 4 batches with FCI on constant cough). However, seven of these batches had 354 current partial condemnation rates of less than $9 \%$ and therefore could have been suitable for 355 visual meat inspection only. Nevertheless, the high condemnation rates for the previous year 356 or reporting cough in FCI for the current slaughter batches indicated that it would have been 357 appropriate to carry out additional inspection procedures.

359 We suggest that batches with two points or more (last year's partial condemnation rate over $3608 \%$ or FCI declarations for constant coughing in the current slaughter batches) should be 361 indications for additional meat inspection procedures. Sensitivity and specificity of the 362 scoring method were calculated (Table 4). Current batches with high partial condemnation 363 rates (>9\%) were classified as not to have been suitable for visual meat inspection only. With 364 this classification, the worst eighth of the batches were classified as unsuitable for visual meat 365 inspection alone.

TABLE 4 Sensitivity and specificity of the scoring system to find slaughter batches of 368 pigs unsuitable for visual meat inspection

370 The sensitivity of the scoring system to identify the batches that were unsuitable for visual 371 meat inspection was 55\% (95\% confidence interval: $28-79 \%)$. Specificity to identify batches 

batches unsuitable for visual meat inspection was 86\% (CI95: 77-92 \%).

\section{DISCUSSION} safety and prevents animal diseases (Nieminen, 2015).

suitable for visual meat inspection was 91\% (CI95: 82-95\%). The accuracy of identifying the

The main purpose of the FCI is that the pig producer declares that there are no restrictions to normal slaughter regarding public health, animal health or animal welfare issues. By the FCI form, certain disease symptoms must be declared to provide potentially important and useful information to the $\mathrm{OV}$ who might then decide on additional inspection procedures and also to the slaughterhouse that processes the pigs. At present, the information obtained in the Finnish FCIs is not accurate enough for its purpose and more guidance for farmers is needed to improve and unify their reporting procedures. For instance, the farmers report some inaccurate information due to the time-lag between sending the FCI form and the delivery of pigs for slaughter. This is because some farmers submit the FCI form at the same time as they announce their intention to send pigs for slaughter and they usually do not review the FCI before the actual delivery of pigs (Nieminen, 2015). The farmers also found it difficult to assess the number of animals in the finishing batch with specific symptoms (Nieminen, 2015). Such information is essential for conditions as abscesses or tail biting. Another recent study in which a questionnaire was sent to the OVs, official auxiliaries, slaughterhouse representatives and the central authorities in Finland, found that the respondents experienced serious problems in receiving accurate FCIs (Luukkanen et al., 2015). Nonetheless, the Finnish farmers seem to regard FCI with high motivation. In response to a recent non-peer reviewed questionnaire, Finnish farmers $(n=153)$ opined that the currently used FCI improves food 
In this study we explored the prior information given currently by the Finnish FCI, associated

397 it with meat inspection results, and studied their potential as valuable information at the time 398 of slaughter. As a result, well-chosen signs such as cough, with proper guidelines for 399 reporting were shown as a useful contribution to the FCI in order to allocate pigs for visual 400 meat inspection. In addition, the FCI could be used to assess the likelihood of condemnation 401 in meat inspection.

402

403 We expected to find differences between those pig-batches for which some FCI information was declared compared to those pig-batches for which nothing was declared on. Surprisingly, 405 batches with "nothing to declare" had poorer meat inspection results than the batches that did 406 declare. However, information in FCIs about constant coughing during the three months prior 407 to slaughter seems to be an important predictor, as those batches with declared cough had 408 higher partial condemnation and arthritis rates. Condemnations had not resulted from higher 409 pneumonia rates as one might assume. Pleuritis rates were slightly, but not significantly 410 higher for batches with declared cough. It should be noted that coughing was rare among the 411 studied batches, which might have overall affected the result. In Finland, Actinobacillus 412 pleuropneumoniae (APP) is a significant cause of respiratory infections in growing pigs 413 (Finnish Food Safety Authority Evira, 2014). This quite common pathogen is not a pork414 borne hazard for the consumer. Chronic APP-cases have a cough accompanied by pleural 415 adhesions and abscesses (Gottschalk, 2012). Consequently, the partial condemnations in the 416 present study might be due to more severe pleuritis and pleural abscesses. Declarations on 417 constant coughing always need additional inspection procedures, as they seem to predict 418 higher frequency of meat inspection findings. 
Significant correlations between the FCI reporting and the subsequent findings of bitten tails

421 might also have been expected, but that was not the case. One explanation for the lack of correlation could be the high number of false reports regarding bitten tails. This suggests that proper guidelines, information and training about the FCI system are needed in order that the

424 producers will provide more useful and reliable information on the animals that are about to 425 be slaughtered. More reliable reporting for bitten tails in the FCI could be especially valuable, as findings of bitten tails positively correlate with the partial condemnation rate and with abscesses. Consequently, this study demonstrates that FCI could indicate when additional inspection procedure is appropriate.

The batches of medicated pigs had fewer condemned livers, which is logical because some of 431 the declared medications were probably ascaris deworming treatments. This has been also 432 found in previous studies (Harbers et al., 1992).

434 Most of the condemnations are not food safety issues (EFSA, 2011). Meat is judged "not fit 435 for human consumption" usually because of meat quality aspects and to prevent animal 436 diseases and occupational hazards (EFSA, 2011). Meat inspection is also a key component of 437 the overall surveillance system for pig health and welfare and therefore, additional inspection 438 procedures should be done whenever relevant abnormalities are seen or suspected (EFSA, 439 2011).

441 Besides data on the pigs that are about to be slaughtered and given by the FCI, in this study 442 the usefulness of historical data regarding post mortem meat inspection findings of pigs 443 produced on the same holding was considered. Vial et al. (2015) proposed a risk based animal 444 health surveillance system, aimed at farms with reoccurring health problems, i.e. a history of 
445 above average condemnation rate. Harbers et al. (1991) concluded that previous post-mortem 446 meat inspection findings cannot be used as predictor, partly because of great variation 447 between individual shipments, but it could play a role signaling farms that are likely to deliver 448 pigs with higher level of abnormalities. In this study, we explored the possibility to overcome 449 the problem of unexpected variation between individual shipments with reliable FCI and prior 450 historical data, and created a simple scoring system of slaughter batches to facilitate the 451 current visual meat inspection system. As a result, we found that a simple scoring system of 452 batches according to thresholds obtained from previous meat inspection results and the FCI 453 could be useful. The batches could be sorted in advance according to likelihood of 454 condemnations before their arrival at the slaughterhouse, and then at the time of slaughter to 455 facilitate the OV in deciding the need for any additional inspections.

457 Using FCI to predict meat inspection findings or to make risk assessment for slaughter 458 batches has been found to be problematical in previous studies in other European countries 459 (Meemken, 2006; Windhaus et al., 2007; van Wagenberg et al., 2012; Lupo et al., 2013; 460 Blaha, 2012). It seems that in previous studies (Meemken, 2005; Ellerbroek, 2007) the 461 adjusted threshold limits were concentrated on finding the best batches and directing them to visual meat inspection only. Visual meat inspection is now the new norm, though the emphasis has shifted towards finding the worst batches, which should then be directed to 464 more rigorous inspection procedures. Dickhaus et al. (2009) have done a major work to create 465 a herd health score (HHS)-index that reflects the general health status of pig groups. The 466 HHS can be used to estimate the herd health of the slaughter pigs and for risk-based meat 467 inspection. However, the HHS is designed to reflect the overall health status of the pig group 468 and not specifically for finding groups that need additional inspection procedures in the 469 current visual meat inspection system. 
471 The simple scoring system introduced here, can be easily used as additional information to 472 direct batches to the appropriate meat inspection procedures. Practically it is suggested that 473 batches with a FCI declaration on constant coughing or a batch that comes from a holding 474 with the previous year's partial condemnation rate $\geq 8 \%$, both would be considered candidates 475 for additional inspections. The thresholds can be individually adjusted in every 476 slaughterhouse, because the capacity of the detain rail varies. The majority of the batches 477 studied here would have been directed to the appropriate inspection procedures by our scoring 478 system. Nevertheless, there were few batches that were determined as potential for visual 479 inspection, but which did not qualify. These slaughter batches might include considerable 480 numbers of remnant pigs collected from several compartments of the holding. Such pigs 481 typically are not the best ones. It was very typical that our data contained some batches with 482 high condemnation rates and that the correlations we obtained did not apply to them. One would expect the farmer to have noticed something unusual in the animal batch during 484 fattening, when the partial condemnation rate for the batch increases to over $10 \%$. The only 485 solution to find beforehand these remnant and outliner batches, is to improve the reliability of 486 the FCI reporting and to include prior information on irregular slaughter batches. Before 487 taking the suggested scoring system into practice, more testing for the precise selection of 488 indicators are needed. This pilot study was based on data covering approximately $10 \%$ of the 489 Finnish finisher pig production sites with historical data on app. $13 \%$ of the annually 490 produced pigs, a coverage that can be regarded as representative. But since only one slaughter 491 batch per a producer was regarded by the FCI, some indicator signals might overlooked. 492 Despite all, with this data we managed to show the potential for pre-scoring of incoming 493 slaughter batches. 
495 To include the public health aspect, seroprevalences of the most relevant zoonoses were

496 studied and compared to meat inspection findings. The presence of antibodies to a specific

497 pathogen indicates that the animal has been exposed to the pathogen at some stage of life,

498 although the seropositive animal may no longer be infective (Nielsen et al., 1995; Nielsen et 499 al., 1996). The positive correlation we found between the current seroprevalence of 500 Salmonella and previous year's pneumonia and pleuritis findings during meat inspection 501 could be just a coincidence. However, Smith et al. (2011) reported positive associations 502 between enzootic pneumonia-like lesions and Salmonella -seropositivity. They suspected the 503 reason to be shared risk factors. Finland is virtually free from enzootic pneumonia (Sikava 504 voluntary health monitoring system covering over $97 \%$ of production, www.sikava.fi). No 505 other correlations between serology and meat inspection result were found, as expected. The 506 main zoonotic pathogens do not yield gross pathological findings. Serological profiles are the 507 way to control and monitor these risks rather than visual or traditional meat inspection (Felin et al., 2015). Serological profiles included in the FCI could help differentiate incoming 509 slaughter batches in respect to the risk of main zoonotic pathogens. Thereafter, the meat from 510 these high risk batches could be directed to appropriate heat- or freezing-based treatments 511 when needed. At the farm level, serological monitoring could assist targeting the preventive risk management practices aiming to reduce the occurrence of main zoonotic pathogens in 513 pigs.

\section{CONCLUSIONS}

516 This study found that meat inspection results of currently slaughtered batches are best 517 predicted by previous meat inspection results of pigs from the same holding. Regarding the 518 current FCI reports, declaration for constant coughing within the three months prior to 519 slaughter, revealed as the most relevant sign to predict meat inspection results. To facilitate 
the allocation of pigs for visual inspection, historical meat inspection results of pigs from the

521 same holding and well-chosen symptoms and signs with proper guidelines for reporting

522 should be included in the FCI. These results show that pre-scoring of incoming slaughter

523 batches can improve the FCI system and may be applicable also at EU level. A simple scoring 524 system was introduced that can be easily used as additional information to direct batches to 525 the appropriate meat inspection procedures. Our scoring system can be further improved after 526 reliability and uniformity of the FCI data are achieved. The FCI is an important part of the 527 modern food safety assurance system, and it is the tool to inform the slaughterhouse on any 528 condition at the holding or of the pigs that could compromise food safety or animal health. 529 Most of the zoonoses relevant to pig meat safety appear as latent infections, and since the 530 animals are asymptomatic the current FCI is not providing any useful information to control 531 these biological hazards. To detect the pigs affected by zoonoses relevant for food safety, the 532 FCI should also include surveillance information such as serological monitoring profiles of 533 pigs raised on the same holdings (Felin et al., 2015).

\section{ACKNOWLEDGEMENTS}

536 This study was supported by research funding from the Ministry of Agriculture and Forestry, 537 Finland (1933/312/2011). The official veterinarians, the auxiliaries and the staff of 538 slaughterhouse are gratefully acknowledged for their cooperation.

\section{DECLARATION OF INTEREST}

541 Elias Jukola is the Manager of Corporate Responsibility for HKScan Corporation.

542 Saara Raulo is the head of the Finnish Zoonosis Centre at the Finnish Food Safety Authority 543 Evira. 
546 Blaha, T., 2012. One world-one health: The threat of emerging diseases. A European

547 perspective. Transboundary and Emerging Diseases, 59 (Suppl. 1), 3-8.

548 Dickhaus, C., Meemken, D., \& Blaha, T., 2009. Attemps to quantify the health status of pig

549 herds: developing and valiating a Herd Health Score (HHS), In Aland, A., \& Madec, F.,

550 Sustainable animal production. The challences and potential developments for professional

551 farming. (pp. 191-201).

552 EFSA, 2011. Scientific opinion on the public health hazards to be covered by inspection of 553 meat (swine). 9, 2351.

554 Ellerbroek, L., 2007. Risk based meat hygiene - examples on food chain information and

555 visual meat inspection. DTW.Deutsche tierarztliche Wochenschrift, 114, 299-304.

556 European Commission, 2014. Commission regulation (EU) No 219/2014 of 7 March 2014

557 amending Annex I to Regulation (EC) No 854/2004 of the European Parliament and of the

558 Council as regards the specific requirements for post-mortem inspection of domestic swine.

559 European Parliament and Council, 2004. Regulation (EC) No 854/2004 of the European

560 Parliament and of the Council of 29 April 2004 laying down specific rules for the

561 organisation of official controls on products of animal origin intended for human

562 consumption.

563 Felin, E., Jukola, E., Raulo, S., \& Fredriksson-Ahomaa, M., 2015. Meat juice serology and 564 improved food chain information as control tools for pork-related public health hazards.

565 Zoonoses and public health, 62, 456-464.

566 Finnish Food Safety Authority Evira, 2014. Animal diseases in Finland 2013. Evira

567 publications, $3,16$.

568 Gottschalk, M., 2012. Actinobacillosis, In Zimmerman, J. J., Karriker, L. A., Ramirez, A., 569 Schwartz, K. J., \& Stevenson, G. W. (eds.)., Diseases of Swine (pp. 653-665). US: Wiley570 Blackwell.

571 Harbers, A. H., Smeets, J. F., \& Snijders, J. M., 1991. Predictability of post mortem 572 abnormalities in shipments of slaughter pigs as an aid for meat inspection. The Veterinary 573 quarterly, 13, 74-80.

574 Harbers, A. H., Snijders, J. M., Smeets, J. F., Blocks, G. H., \& van Logtestijn, J. G., 1992. 575 Use of information from pig finishing herds for meat inspection purposes. The Veterinary 576 quarterly, 14, 41-45.

577 Lupo, C., Le Bouquin, S., Balaine, L., Michel, V., Peraste, J., Petetin, I., Colin, P., Jouffe, L., 578 \& Chauvin, C., 2013. Bayesian network as an aid for Food Chain Information use for meat 579 inspection. Preventive veterinary medicine, 109, 25-36. 
Meemken, D., 2006. Research on evaluation systems for food chain information being used in 584 the risk-based ante- and post-mortem meat inspection of slaughter pigs. Doctoral dissertation.

585 Meemken, D., 2005. Generating valid food chain information for the risk-based meat 586 inspection (reg. 854/2004/EC). In Proceedings in XIIth International Congress on Animal 587 Hygiene (358-360). Warsaw, Poland.

588 Nielsen, B., Baggesen, D., Bager, F., Haugegaard, J., \& Lind, P., 1995. The serological 589 response to Salmonella serovars typhimurium and infantis in experimentally infected pigs. 590 The time course followed with an indirect anti-LPS ELISA and bacteriological examinations. 591 Veterinary microbiology, 47, 205-218.

592 Nielsen, B., Heisel, C., \& Wingstrand, A., 1996. Time course of the serological response to 593 Yersinia enterocolitica O:3 in experimentally infected pigs. Veterinary microbiology, 48, 293594303.

595 Nieminen, T., 2015. Ketjuinformaatio antaa tietoa, turvaa ja varmuutta. (Food chain 596 information gives information, safety and assurance). AtriaTuottaja, 1, 22-23.

597 Smith, R. P., Sanchez-Vazquez, M. J., Cook, A. J., \& Edwards, S. A., 2011. Abattoir-based 598 study investigating the association between gross pathological lesions and serological tests for 599 Salmonella infection in pigs. The Veterinary record, 168, 240-244.

600 van Wagenberg, C. P., Backus, G. B., van der Vorst, J. G., \& Urlings, B. A., 2012. Usefulness 601 of food chain information provided by Dutch finishing pig producers to control antibiotic 602 residues in pork. Preventive veterinary medicine, 107, 142-145.

603 Vial, F., Scharrer, S., \& Reist, M., 2015. Risk factors for whole carcass condemnations in the 604 Swiss slaughter cattle population. PloS one, 10, e0122717.

605 Windhaus, A., Meemken, D., Blaha, T., \& Klein, G., 2007. Results of the evaluation of food 606 chain information for a risk-oriented meat inspection. DTW.Deutsche tierarztliche 607 Wochenschrift, 114, 305-308. 
1 TABLE 1 Data collected on randomly selected 85 slaughter batches of finishing pigs

2 from Finnish slaughterhouse

\begin{tabular}{|c|c|c|c|c|}
\hline $\begin{array}{l}\text { A. Food chain } \\
\text { information regarding } \\
\text { the holding }\end{array}$ & \multicolumn{2}{|c|}{$\begin{array}{c}\text { \% (number) of batches } \\
(\mathrm{n}=85)\end{array}$} & $\begin{array}{c}\text { \% of pigs in } \\
\text { current } \\
\text { batches } \\
(\mathrm{n}=8954)\end{array}$ & $\begin{array}{l}\text { Of } \\
\text { concern } \\
\text { to }\end{array}$ \\
\hline Salmonellosis occurred & \multicolumn{2}{|c|}{0} & 0 & $\mathrm{P}$ \\
\hline Trichinellosis occurred & \multicolumn{2}{|c|}{0} & 0 & $\mathrm{P}$ \\
\hline Erysipelas occurred & \multicolumn{2}{|c|}{$3.5(3)$} & $\mathrm{n} / \mathrm{a}$ & $\mathrm{P}$ \\
\hline Official restrictions & \multicolumn{2}{|c|}{0} & 0 & $\mathrm{~A} / \mathrm{P}$ \\
\hline $\begin{array}{l}\text { Drug residues detected in } \\
\text { animals }\end{array}$ & \multicolumn{2}{|c|}{0} & 0 & $\mathrm{P}$ \\
\hline $\begin{array}{l}\text { B. Food chain } \\
\text { information regarding } \\
\text { the batch }\end{array}$ & \multicolumn{2}{|c|}{ 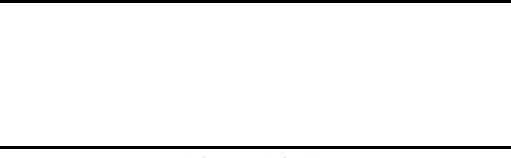 } & & $\begin{array}{c}\text { Of } \\
\text { concern } \\
\text { to }\end{array}$ \\
\hline $\begin{array}{l}\text { Includes pigs medicated within } \\
\text { the last } 3 \text { months }\end{array}$ & \multicolumn{2}{|c|}{$52.9(45)$} & $\mathrm{n} / \mathrm{a}$ & $\mathrm{A} / \mathrm{P}$ \\
\hline Includes pigs with hernia & \multicolumn{2}{|c|}{$35.3(30)$} & 0.7 & $\begin{array}{c}\mathrm{W} /(\mathrm{P}, \\
\text { higher } \\
\text { risk of } \\
\text { fecal } \\
\text { contamina } \\
\text { tion) }\end{array}$ \\
\hline $\begin{array}{l}\text { Includes pigs with } \\
\text { abscesses/lumps }\end{array}$ & \multicolumn{2}{|c|}{$21.2(18)$} & 0.4 & $\mathrm{~W}$ \\
\hline Includes lame pigs & \multicolumn{2}{|c|}{$15.3(13)$} & 0.3 & $\mathrm{~W}$ \\
\hline Includes pigs with bitten tails & \multicolumn{2}{|c|}{$44.7(38)$} & 1.4 & $\mathrm{~W}$ \\
\hline $\begin{array}{l}\text { Constant coughing in three } \\
\text { months prior to slaughter: a bit } \\
\text { / a lot }\end{array}$ & \multicolumn{2}{|c|}{$4.7(4) / 0.0$} & $\mathrm{n} / \mathrm{a}$ & $\mathrm{A}$ \\
\hline \multirow[t]{2}{*}{$\begin{array}{l}\text { C. Meat inspection } \\
\text { results }\end{array}$} & \multicolumn{2}{|c|}{ Study data } & Official & $\begin{array}{c}\text { Of } \\
\text { concern }\end{array}$ \\
\hline & $\begin{array}{l}\text { Mean \% } \\
\text { (variation } \\
\text { interval) } \\
\text { of batches } \\
(\mathrm{n}=85)\end{array}$ & $\begin{array}{c}\text { Mean \% } \\
\text { (variation } \\
\text { interval) of } \\
\text { holding } \\
\text { results* } \\
(\mathrm{n}=80)\end{array}$ & $\begin{array}{l}\text { \% of all } \\
\text { fattening pigs } \\
\text { slaughtered in } \\
\text { Finland } 2013\end{array}$ & \\
\hline Total condemnation & $0.2(0.0-2.9)$ & $0.3(0.0-3.4)$ & 0.3 & $\mathrm{~A} / \mathrm{P}$ \\
\hline Partial condemnation & $5.0(0.0-17.6)$ & $\begin{array}{l}5.6(1.5- \\
23.9) \\
\end{array}$ & 6.4 & $\mathrm{~A} / \mathrm{W}$ \\
\hline Condemned organs & $1.6(0.0-19.5)$ & $\begin{array}{l}1.7(0.2- \\
11.7)^{\circ}\end{array}$ & $\mathrm{n} / \mathrm{a}$ & $\mathrm{A} / \mathrm{W} / \mathrm{P}$ \\
\hline Pneumonia & $3.8(0.0-29.2)$ & $\begin{array}{c}2.0(0.0- \\
11.7)\end{array}$ & 2.2 & $\mathrm{~A}$ \\
\hline
\end{tabular}




\begin{tabular}{|c|c|c|c|c|}
\hline Pleuritis & $\begin{array}{l}35.0(1.7- \\
90.0)\end{array}$ & $\begin{array}{l}17.8(0.0- \\
58.8)\end{array}$ & 15.9 & $\mathrm{~A}$ \\
\hline Pericarditis & $3.6(0.0-32.9)$ & $\mathrm{n} / \mathrm{a}$ & 2.3 & A \\
\hline Condemned livers & $9.1(0.0-54.4)$ & $\begin{array}{l}6.0(0.0- \\
52.5)\end{array}$ & 6.3 & $\bar{A}$ \\
\hline Arthritis & $1.7(0.0-17.6)$ & $\begin{array}{l}2.4(0.6- \\
18.0)\end{array}$ & 3.0 & $\mathrm{~W}$ \\
\hline Bitten tails & $1.5(0.0-8.3)$ & $\begin{array}{l}0.5(0.0- \\
1.7)^{\circ}\end{array}$ & 1.0 & $\mathrm{~W}$ \\
\hline Abscesses & $4.1(0.0-12.9)$ & $\begin{array}{c}4.5(0.0- \\
11.3) \\
\end{array}$ & 3.2 & $\mathrm{~A} / \mathrm{W}$ \\
\hline $\begin{array}{l}\text { Findings related to } \\
\text { Mycobacterium avium complex }\end{array}$ & $0.5(0.0-6.8)$ & $0.4(0.0-4.7)$ & 0.3 & $\mathrm{P}$ \\
\hline $\begin{array}{l}\text { D. Serological analysis } \\
\text { results }\end{array}$ & \multicolumn{2}{|c|}{$\begin{array}{c}\text { Positive batches**, \% } \\
(\mathrm{n}=85)\end{array}$} & $\begin{array}{c}\text { Positive pigs, } \\
\% \\
(n=431)\end{array}$ & $\begin{array}{c}\text { Of } \\
\text { concern } \\
\text { to }\end{array}$ \\
\hline Salmonella spp. & \multicolumn{2}{|c|}{14.1} & 3.5 & $\mathrm{P}$ \\
\hline Pathogenic Yersinia spp. & \multicolumn{2}{|c|}{81.2} & 56.1 & $\mathrm{P}$ \\
\hline Trichinella spp. & \multicolumn{2}{|c|}{0.0} & 0.0 & $\mathrm{P}$ \\
\hline Toxoplasma gondii & \multicolumn{2}{|c|}{8.2} & 2.6 & $\mathrm{P}$ \\
\hline E. Other data & \multicolumn{2}{|c|}{$\begin{array}{c}\text { Mean of batches, \% } \\
\text { (variation interval) }\end{array}$} & & $\begin{array}{c}\text { Of } \\
\text { concern } \\
\text { to } \\
\end{array}$ \\
\hline $\begin{array}{l}\text { Mortality rate of the batch } \\
\text { during the fattening period }\end{array}$ & \multicolumn{2}{|c|}{$1.7(0.0-8.4)^{* * * * *}$} & $\mathrm{n} / \mathrm{a}$ & $\mathrm{A} / \mathrm{W}$ \\
\hline
\end{tabular}

3 Note: $\mathrm{A}=$ animal health; $\mathrm{W}=$ animal welfare; $\mathrm{P}=$ public health; adapted from EFSA, 2011

$4 *$ holding result $=$ result of all pigs slaughtered from the holding the previous year

$5 \quad * *$ meat inspection statistics 2013, Food Safety Authority Evira

$6 * * * 3-10$ pigs per batch tested

$7 * * * *$ data from Sikava - Stakeholders health and welfare register for pig herds in Finland,

8 available for $82 / 85$ batches

9 oprevious years meat inspection data considering organ condemnations and bitten tails was

10 available for $31 / 80$ holdings

$11 \mathrm{n} / \mathrm{a}=$ not available 
TABLE 2 Statistically significant correlations $(p<0.05)$ between meat inspection results for the currently slaughtered batch $(n=85)$ and between meat inspection results for pigs

sent from the same holding for slaughter the previous year

\begin{tabular}{|l|l|l|l|l|}
\hline Currently slaughtered & Slaughtered pigs from & $\begin{array}{l}\text { Pearson } \\
\text { correlation } \\
\text { coefficient }\end{array}$ & p-value & $\begin{array}{l}\text { Number } \\
\text { of } \\
\text { batches } \\
\text { concern }\end{array}$ \\
& previous year & & & \\
& & & & \\
\hline partial condemnations, & partial condemnations \%, & 0.32 & $<0.01$ & 85 \\
& abscesses \%, & 0.37 & $<0.01$ & 85 \\
& bitten tails \% & 0.42 & 0.02 & 31 \\
\hline organ condemnations, & organ condemnations \%; & 0.42 & 0.02 & 31 \\
\%leuritis \%; & -0.25 & 0.02 & 85 \\
& pneumonia \% & -0.23 & 0.03 & 85 \\
\hline abscesses, \% & abscesses \%; & 0.41 & $<0.01$ & 85 \\
& bitten tails \%; & 0.51 & $<0.01$ & 31 \\
& partial condemnations\% & 0.31 & $<0.01$ & 85 \\
\hline bitten tails, \% & bitten tails \%; & 0.45 & 0.01 & 31 \\
& abscesses \% & 0.35 & $<0.01$ & 85 \\
\hline pleuritis, \% & pleuritis, \% & 0.28 & $<0.01$ & 85 \\
\hline pericarditis, \% & organ condemnations \%; & 0.91 & $<0.01$ & 31 \\
& liver condemnations \% & 0.27 & 0.01 & 85 \\
\hline liver condemnation, \% & liver condemnations \%; & 0.56 & $<0.01$ & 85 \\
& organ condemnations \% & 0.63 & $<0.01$ & 31 \\
\hline Mycobacterium avium & Mycobacterium avium - & 0.30 & $<0.01$ & 85 \\
- complex, \% & complex, \% & & & \\
\hline & & & & \\
\hline
\end{tabular}

TABLE 3 Scoring of 85 batches of slaughter pigs according to food chain information provided

\begin{tabular}{lccccc}
\hline Scouring points & 0 & 1 & 2 & 3 & 4 \\
\cline { 2 - 6 } $\begin{array}{l}\text { Previous year's partial } \\
\text { condemnation rate }\end{array}$ & $<3 \%$ & $3-8 \%$ & $>8 \%$ & $3-8 \%$ & $>8 \%$ \\
$\begin{array}{l}\text { Declaration for } \\
\text { constant cough }\end{array}$ & no & no & no & yes & yes \\
$\begin{array}{l}\% \text { of batches } \\
\text { n }\end{array}$ & 9.4 & 75.3 & 10.6 & 4.7 & 0.0 \\
\hline
\end{tabular}


29 TABLE 4 Sensitivity and specificity of the scoring system to find slaughter batches of

30 pigs unsuitable for visual meat inspection

\begin{tabular}{|l|l|l|l|}
\hline & $\begin{array}{l}\text { Previous year's } \\
\text { partial condemnation } \\
\text { rate }>8 \% \text { or reported } \\
\text { cough }\end{array}$ & $\begin{array}{l}\text { Previous year's } \\
\text { partial condemnation } \\
\text { rate } \leq 8 \% \text { no reported } \\
\text { cough }\end{array}$ & ( \\
\hline $\begin{array}{l}\text { Batches unsuitable } \\
\text { for visual meat } \\
\text { inspection }\end{array}$ & 6 & 5 & 11 \\
\hline $\begin{array}{l}\text { Batches suitable for } \\
\text { visual meat } \\
\text { inspection }\end{array}$ & 7 & 67 & 74 \\
\hline Total & 13 & 72 & 85 \\
\hline
\end{tabular}

31 Sensitivity $55 \%$ (95\% confidence interval 28-79\%) and specificity $91 \%$ (CI95: 82-95\%).

32 


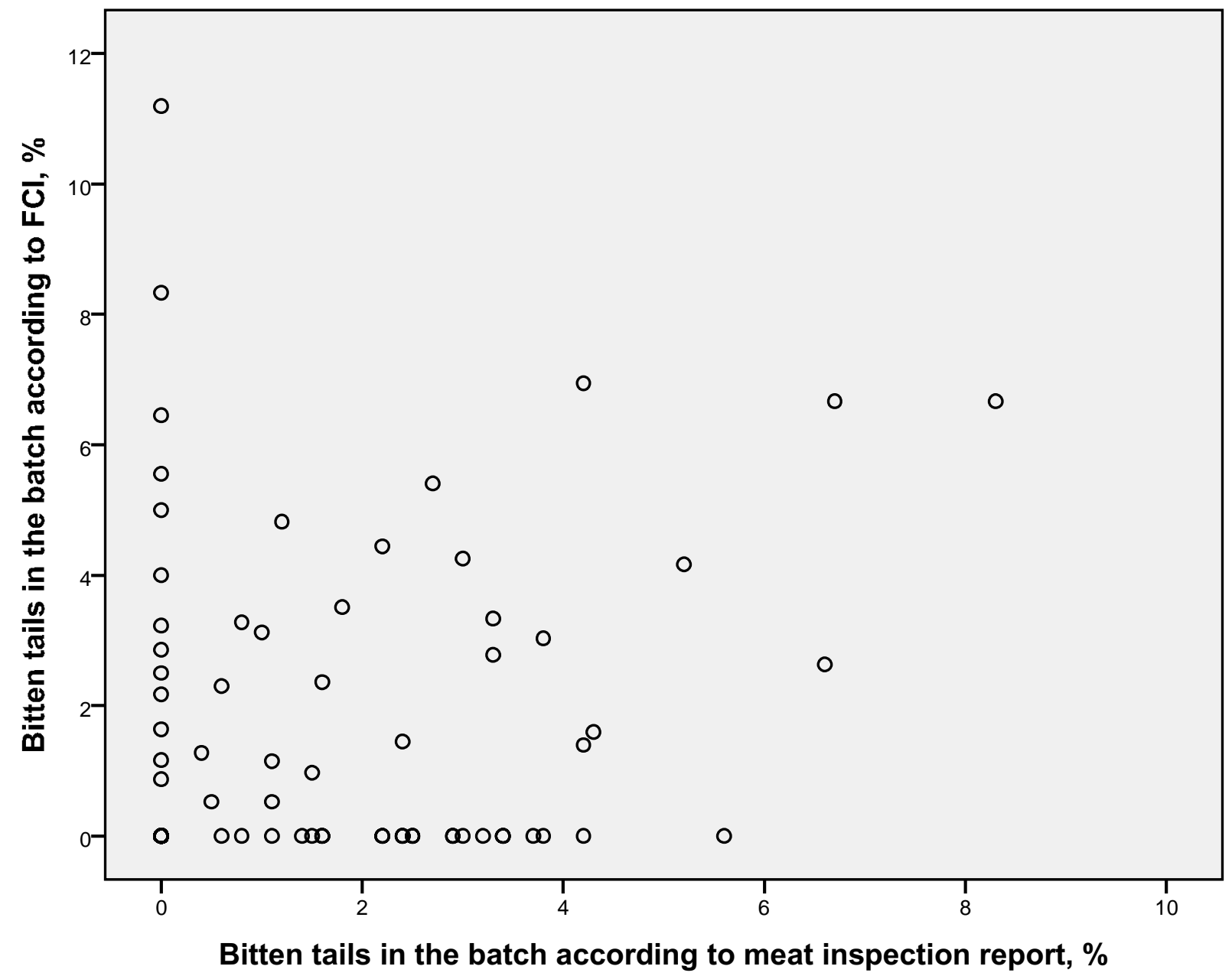

Page 1 


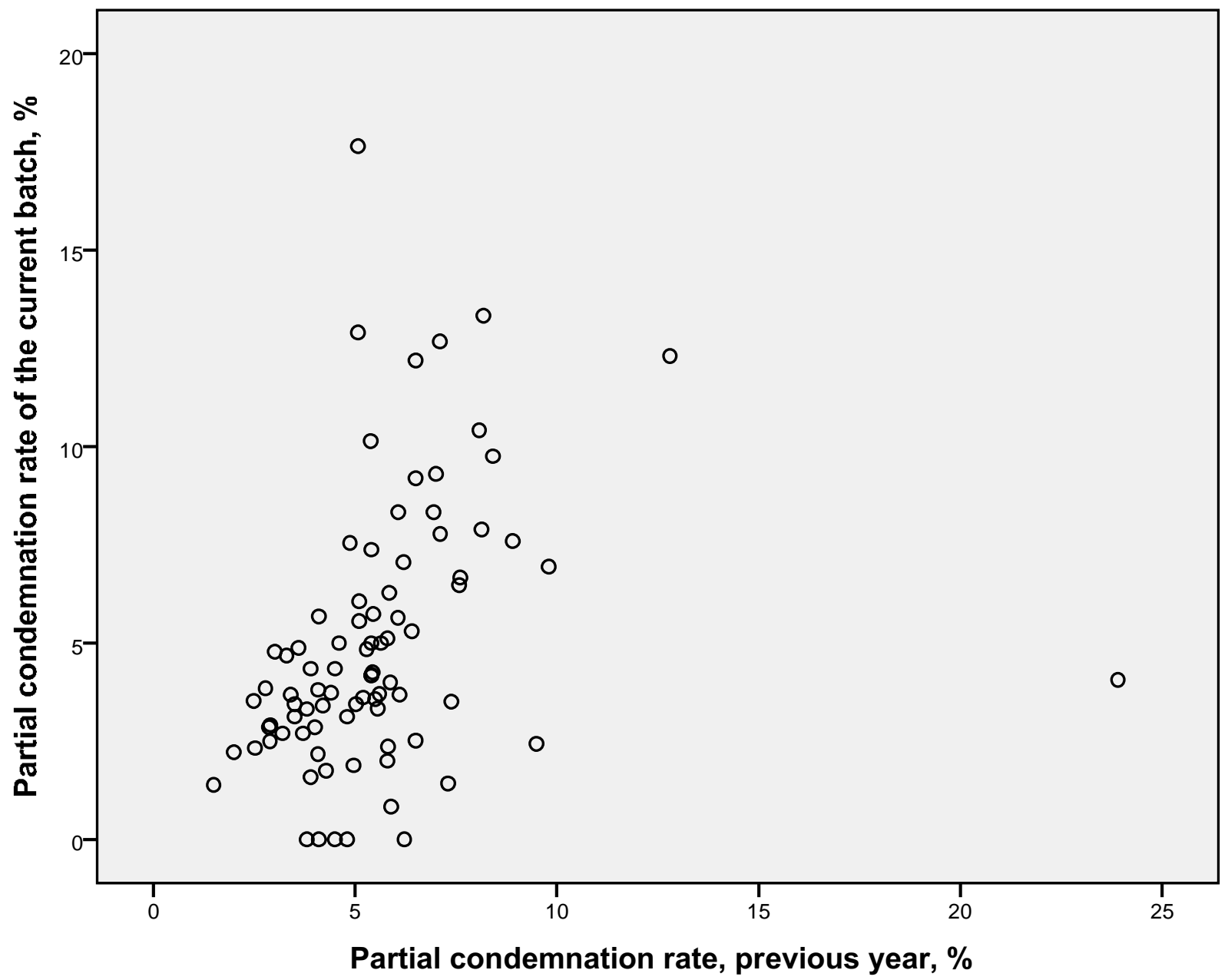

